\title{
Reflexões sobre a figura do arquivamento implícito no processo penal
}

\author{
Reflections on the picture of implicit filing in criminal procedure
}

\author{
Carlos Frederico Manica Rizzi Cattani ${ }^{1}$ \\ Mestre em Ciências Criminais pela PUCRS, Porto Alegre, RS
}

\begin{abstract}
RESUMO: Este artigo discorre sobre o arquivamento implícito (ou tácito) no processo penal brasileiro e enfrenta a matéria por meio da doutrina e jurisprudência. $\mathrm{O}$ tema é de grande relevância, pois não encontra previsão expressa na legislação pátria, resultando em debates de construção teoria para sua aplicabilidade. $\mathrm{O}$ assunto é enfrentado delimitando categorias próprias do processo penal, como a dignidade da pessoa humana, os limites de tempo para a persecução penale a (in)divisibilidade da ação penal de iniciativa pública.
\end{abstract}

Palavras-chave: Ação Penal Pública. Inquérito Policial. Arquivamento implícito. Dignidade da pessoa humana.

ABSTRACT: This article discusses the implicit filing in Brazilian criminal procedure and faces criminal matter through the doctrine and jurisprudence. The subject is of great importance, because there is no express provision in the legislation homeland, resulting in discussions of theory building to its applicability. The text are delimiting own categories of criminal procedure, such as the dignity of the human person, if are time limits for prosecution and (in)divisibility of public action.

Keywords: Criminal procedure. Criminal investigation;. Implicit filing. Dignity of the Human person.

\section{INTRODUÇÃO: PARTE I}

Em uma breve reflexão e tendo como ponto de partida a sanção penal, nos dizeres de COSTA (2010, p. 19), esta representa aquilo que os homens de certa comunidade consideram comportamentos proibidos, sendo que "a pena é, por sobre tudo, a refracção do entendimento do homem sobre si próprio", leia-se, "valores dessa comunidade em um certo tempo e em um certo espaço". Neste sentido, o direito penal ocupa o lugar jurídico de declarar as condutas humanas que devem ser repreendidas, impondo a forma e os limites para valorar uma evitação e, ocorrendo, incutir arrependimento ao desviante. No entanto, impossível não pensar que o processo penal também é, por si só - para o acusado - a aplicação de uma pena, mesmo antes de qualquer sentença (que a declare), seja, inclusive, a absolutória. Sob o título "As misérias do processo penal”, CARNELUTTI $(2009$, p. 66) captura um cenário reflexivo, no qual, partindo do princípio de não-culpabilidade previsto na Constituição Italiana, encontra uma norma que serve à boa-fé daqueles que a elaboraram, forjando ilusões, apurando que: "Infelizmente, a justiça humana está feita de tal maneira que não somente se faz sofrer os homens porque são culpados, senão também para saber se são culpados ou inocentes".

Esta sua condição faz refletir e repousar as expectativas dos valores da comunidade sobre aquele quem caminha por um processo penal. Por isso, talvez e também, o próprio CARNELUTTI tenha sinalizadoo sofrer como algo intrínseco, enraizado, uma necessidade "à qual o processo não pode se subtrair”. Ora,em uma frágil e prévia hipótese, vislumbra-se como taxado ao mundo jurídico ir muito além do entendimento do processo enquanto um sofrimento diverso da pena (libertador) - e dos dados que o desvelam como uma rotulação para poucos $^{2}$. Por isso uma crítica egoística em favor do indivíduo-réu, pois para a comunidade enquanto de massas, e fonte de valores regidos por determinantes invisíveis, estas não constroem as categorias por meio de garantias individuais. Logo, o processo penal não pode ser fundando em expectativas e clamores sociais, edificados em visões opacas e reducionistas. Sobre discursos contra impunidade geral, mais forte deve ser o instrumento constitucional que freie a voz autoritária. 
O pensamento aqui, permissa vênia, seria como encarar a criação desarrazoada de normas penais como a fonte das soluções de problemas de políticas públicas. Interessante denotar a alta capacidade de ignorar o que advoga a doutrina contemporânea, em dizeres inclusive anteriores a Constituição de 1988, como em FRAGOSO (1983, p. 4) que enfatizou sero crime um fenômeno sócio-político, "que se deve a um conjunto de fatores ligados à estrutura econômico-social, em relação ao qual o Direito Penal tem muito pouca influência". Então, deve ser frisado insistentemente, não se resolve o problema da criminalidade com Direito Penal e, assim, é inútil tentar evitar ações repreendidas pela comunidade tornando o processo penal um lugar sem garantias.

É inútil legislarsobre todo e qualquer comportamento humano, tendo por objetivo mudar rumos sociais, sem que haja políticas concretas de influência sobre o sistema - o que somente aumenta os números da criminalidade e das cifras negras. Neste sentido, mutatis mutantis, o mesmo que deseja fazer crer na lei penal como solução, vai ingenuamente ter para si que o processo penal é sempre significado de condenação, a pena em si própria - criada, aplicada e sentida. E é preciso ir contra a corrente que tem por desacreditado o processo penal de garantias, estruturado parabuscar (instrumento)uma justa sentença e, a partir desta, sim, haver uma garantia constitucional para execução de penas.

O Estado de Direito Material ${ }^{3}$, nesta conjuntura de garantir garantias e de refletir os valores de uma comunidade, não pode ser - ao menos em nossa posição jurídico-penal -, um espetáculo de separação e afastamento entre o homem e o homem (DEBORD, 1997). Assim como, eficiência e garantismo são vetores que não se opõem, sendo incabível no lugar que ocupa o processo penal, conceber a eficiência na derrocada das garantias constitucionais. ${ }^{4}$ Por isso, este instrumento constitucional que é o processo penal, não se trata somente de avais técnicos, mas reflete em si valores políticos e ideológicos da sociedade em que reside. Razões pelas quais se faz necessário um equilíbrio na concretização de dois interesses fundamentais, quais sejam, "assegurar ao Estado mecanismos para atuar o seu poder punitivo e o de garantir ao indivíduo instrumentos para defender os seus direitos e garantias fundamentais e para preservar a sua liberdade" (FERNANDES, 2012, p. 26).

$\mathrm{E}$, neste ínterim, muito bem demonstra CARVALHO (2009) que o perigo está quando discursos reducionistas colocam e separam (como se fosse possível) os 'direitos' em compartimentos, criando falsas dicotomias e, no exemplo do autor, tornando possível tutelar direitos coletivos sem garantir direitos individuais. Prontamente, para CARVALHO, existe um critério de seleção para os valores, conforme práticas de seleção ideológicas e de discurso simbólico,

Esse método de despedaçamento, típico da obsoleta concepção cartesiana, que funda a ciência Moderna, e que obtém como efeito concepção beligerantes entre os interesses reivindicados e entre os seus legítimos titulares, obscurece o pensamento e a ação voltada à efetivação dos Direitos Humanos (2009, p. 135).

Com tudo isso, o que se quer aprofundar, é um fundante respeito em pesar o objeto pesquisado (arquivamento implícito) de um lugar onde haja garantias e eficiência, mas não somente uma destas ou lendo elas como se não fossem complexas e sobrepostas. Por um diagnóstico, ainda que prévio, o processo penal em sua natureza interna de afirmação ou construção de uma subjetividade, ou em revelar um convencimento dito verdadeiro, também expõe uma relação intersubjetiva e além-muros, que o acusado sente em sofrimento e expectativas, na perspectiva da segurança constitucional sob o seu alento enquanto indivíduo e, assim, pessoa humana que anseia dignidade.

\section{INTRODUÇÃO: PARTE II}

O tema arquivamento implícito possui atualmente uma posição por parte da doutrina, e exarado pelos Tribunais, no sentido de seu não cabimento no processo penal brasileiro, inclusive com manifestações do Supremo Tribunal Federal neste sentido. No entanto, parte dos doutrinadores, chamados de minoria pelos manuais, defende o seu cabimento, alegando tratar-se de uma situação legítima ao indiciado. É de se observar que a grande mistificação do arquivamento implícito está exatamente no fator de ser uma criação doutrinária, pois ausente sua previsão na legislação pátria.

Para trabalhar o assunto, impõe-se destacar quatro critérios maiores, sendo o primeiro que a análise do tema se fará da perspectiva da ação penal de iniciativa pública, e, ainda: a) dignidade da pessoa humana enquanto princípio constitucional norteador do processo penal; b) os limites de tempo para a persecução penal; e, c) a (in)divisibilidade da ação pública. A escolha destes critérios visa a analisar se, mesmo não existindo previsão legal expressa sobre o arquivamento implícito, o mesmo ainda é sustentável enquanto interpretação constitucional das normas. 


\section{RECONHECENDO A MATÉRIA I: DO ARQUIVAMENTO NO PROCESSO PENAL}

A exposição de motivos do Código de Processo Penal brasileiro apresenta o inquérito como um procedimento preparatório (ou não) ao processo penal, assegurando, assim, uma justiça menos aleatória, mais prudente e serena, mantendo, por derradeiro, uma trincheira contra apressados e errôneos juízos antes que seja possível uma visão exata do conjunto dos fatos, nas suas circunstâncias objetivas e subjetivas.

Neste sentido, sobre a finalidade do Inquérito Policial, dispõe o artigo quarto da lei processual penal: "a apuração das infrações penais e da sua autoria".

$\mathrm{O}$ arquivamento do inquérito policial não significa necessariamente que ele não atingiu totalmente sua finalidade. Isto, pois, na perspectiva da figura dos suspeitos e indiciados, não alcançadas pela investigação prévia prova e justificativa para indicar autoria do delito, deve reconhecer a precariedade e errôneo juízo da hipótese primeira, ou seu sobrestamento. Ora, o crime ainda necessita ser desvelado, mas muitas vezes há um direcionamento hipervalorado da hipótese de autoria, que enquanto for frágil não pode justificar um processo penal e uma pretensão acusatória. Conforme destaca LOPES JR. (2013), “o objeto da investigação preliminar é o fato constante na notitia criminis", tendo a autoria "um elemento subjetivo acidental", por isso, "Não é necessário que seja previamente atribuída a uma pessoa determinada".

A lei processual prevê, em seus artigos dezoito e vinte oito, a figura do arquivamento do inquérito, como meio necessário para conter procedimentos investigativos em que não há outras diligências cabíveis para sanar dúvidas e inexiste convencimento prévio para formalizar uma acusação. Ora, contudo, uma vez sobrevindo o pedido de arquivamento, por falta de base para a denúncia, "a autoridade policial poderá proceder a novas pesquisas, se de outras provas tiver notícias". Logo, arquivada a investigação, somente o surgimento de novas provas permite a continuidade da investigação e torna-se condição específica para haver ação penal.

De se ver então, que o arquivamento do inquérito gera direito subjetivo ao investigado, em face da administração pública, na medida em que a reabertura das investigações está condicionada ou subordinada à existência de determinado fato e/ou situação concreta (art. 18 CPP) (PACELLI, 2012, p. 67).

Assim é o entendimento da Súmula 524 do Supremo Tribunal Federal, dispondo que se for determinado o arquivamento do inquérito ou peças de informação, somente poderá ser desarquivado se surgirem novas provas. Não se olvida que o Ministério Público deverá sempre requerer o arquivamento do inquérito "evitando-se uma imputação que jamais chegará a resultado algum" (PACELLI, 2012, p. 67).

GRECO FILHO (2012, p. 110) anota que o rito do arquivamento impede ao juiz interferir no locus do acusador determinando de oficio novas provas ou tomando para si a atribuição de elaborar a denúncia, ressalvando que somente caberia remeter os autos ao Procurador-Geral de Justiça, "sob pena de praticar ato de inversão tumultuária da ordem processual" e agir em desrespeito ao "princípio acusatório e a imparcialidade do juiz". Nesta senda, não sendo deferido o pedido de arquivamento do Inquérito Policial, conclui o autor que deverá o Ministério Público em Cota Introdutória, ao se dirigir ao juiz:

a) declara que apresentou a denúncia em separado;

b) requer diligências que reputar necessárias, inclusive a folha de antecedentes e certidões respectivas;

c) pode justificar o enquadramento legal proposto na denúncia ou tratar de outras questões jurídicas, comopor exemplo, a fundamentação da competência, a inexistência de prescrição etc.;

d) deve justificar a não inclusão como réu de algum indiciado ou o não oferecimento da denúncia em relação a algum fato punível referido no inquérito.

Dentre estas pontuações, destaca-se o item 'd', qual seja, a necessidade de informar a não inclusão de um indiciado como réu na peça acusatória ou a não inclusão de algum fato punível, o qual poderá o Juiz remeter ao Procurador-Geral caso não concorde, nos termos do artigo 28 da lei processual.

\section{RECONHECENDO A MATÉRIA II: DO ARQUIVAMENTO IMPLÍCITO (OU TÁCITO) NO PROCESSO PENAL}

O arquivamento implícito, nas palavras de SILVA JARDIM (2003, p. 170), seria o fenômeno de ordem processual "decorrente de o titular da ação penal deixar de incluir na denúncia algum fato investigado ou algum dos indiciados", sem que tenha para tanto (em Cota Introdutória), expressa manifestação ou justificação para agir daquela maneira. Em outras palavras, seria, em verdade, um arquivamento tácito ${ }^{5}$, deixando o Ministério Público de denunciar um fato ou algum 
dos indiciados, e não havendo manifestação do juiz sobre tal situação, nos termos do artigo 28 do Código de Processo Penal, sobreviria o arquivamento de forma implícita, ou não dita.

A título de exemplo, imaginemos o inquérito que tenha indiciado três delinquentes, pela práticas de duas infrações penais. Caso o promotor denuncie apenas dois deles, e por um único crime, nada requerendo quanto ao indivíduo e a infração faltante, opera-se o chamado arquivamento implícito (TÁVORA, 2013, p. 134).

Assim, o arquivamento é, na verdade, tácito, "decorrendo da omissão do MP e da inércia do juiz" (LOPES JR., p. 318). No entanto, apesar da construção doutrinária afirmando sua ocorrência, existe uma maioria, inclusive pela jurisprudência, que não admite essa modalidade de arquivamento. Dois têm sido os principais argumentos, primeiro porque todo pedido de arquivamento deve ser fundamentado:

[...] perceba-se que o próprio art. 28 do CPP faz menção às razões invocadas pelo Ministério Público. Logo, mesmo que o órgão do Ministério Público não tenha se manifestado expressamente em relação a determinado fato delituoso e/ou coautor ou partícipe, nem tampouco tenha o juiz determinado a aplicação do art. 28 do CPP, não há falar em arquivamento implícito (BRASILEIRO, p. 135).

E, em segundo sentido, pela falta de sua previsão na legislação nacional:

$\mathrm{O}$ arquivamento implícito não foi concebido pelo ordenamento jurídico brasileiro, e modo que nada obsta que o Parquet proceda ao aditamento da exordial acusatória, no momento em que se verificar a presença de indícios suficientes de autoria de outro corréu. ((RHC 113273, Relator(a): Min. LUIZ FUX, Primeira Turma, julgado em 25/06/2013).

No entanto, a relevância da matéria está "na medida em que, operando o arquivamento tácito ou implícito, não caberá aditamento ou nova denúncia em relação àquele fato ou autor, salvo se existirem novas provas" (LOPES JR., 2013. p. 318). Ou seja, até qual momento é possível o parquet denunciar parte dos indiciados no inquérito policial ou dos supostos crimes, sem justificar a ausência dos outros na ação penal, podendo, conforme interesse e conveniência, a estratégia acusatória aditar sem que haja uma vinculação (justificativa) nova (no caso novos elementos)?

Merecido, pois, destacar as palavras de RANGEL (2013,p. 210), para o qual, nas hipóteses de arquivamento implícito, aditamento só caberá se surgirem novas provas, "ou seja, provas que não constavam do inquérito (ou peças de informação), embora já existissem". Em linhas centrais, o arquivamento implícito pode ser "subjetivo (sujeitos) ou objetivo (fatos) ou ainda de elemento derivado da figura típica e ocorre sempre que há não inclusão na denúncia (de fato ou sujeito) e o juiz não adota a providência do art. 28 do CPP" (RANGEL, 2013, p. 210).

Trata-se de tema de grande embate doutrinário e na jurisprudência, por exemplo:

\begin{abstract}
Ocorre arquivamento implícito quando o Ministério Público, ao se manifestar sobre os fatos apurados no inquérito, silencia quanto a provável crime da esfera federal, postulando a declinação da competência para o Juízo Estadual no tocante aos demais delitos, sendo o pedido acolhido pelo julgador. (TRF4, HC 2004.04.01.019824-0, Oitava Turma, Relator Élcio Pinheiro de Castro, DJ 25/08/2004).
\end{abstract}

Neste tocante, o importante é destacar que existe uma maior ou menor aceitação pela tese e existência da referida hipótese de arquivamento, vinculando o aditamento da denúncia à demonstração de novas provas, nos termos do artigo 18 da lei processual e da Súmula 524 do Supremo Tribunal Federal, em que pesa a corrente contrária à aplicação da hipótese.

\section{DIGNIDADE DA PESSOA HUMANA ENQUANTO PRINCÍPIO CONSTITUCIONAL NORTEADOR DO PROCESSO PENAL}

Necessário nortear o discurso com a visão política do processo, isto é, o processo penal enquanto reflexo de um Estado mais ou menos democrático, mais ou menos autoritário. Isto, pois, respeito às garantias (constitucionais) não pode ser confundido ou utilizado como sinônimo de impunidade, o "espaço comum democrático é construído pela afirmação do respeito à dignidade humana" (LOPES JR., p. 63). E, neste liame, imprescindível citar GERALDO PRADO (2010, p. 199):

[...] as chamadas garantias processuais são o passaporte de qualquer Estado para o mundo civilizado. São as primeiras regras desrespeitadas quando surgem os governos autoritários. E, pois, não são suprimíveis quando se trata de postular tratamento racional e humano às causas criminais. $\mathrm{O}$ juiz não pode abdicar das garantias processuais, independentemente de quem esteja sendo processado e da natureza da infração penal atribuída ao acusado. 
Neste sentido, evidenciou-se a necessidade de sistematizar internacionalmente por meio de acordos e tratados (declarações) às garantias humanas, pois "estes instrumentos devem ser levados em conta em qualquer interpretação que se faça do direito penal positivo interno, que não pode entrar em contradição com eles" (ZAFFARONI, 2011, p. 68). A Constituição Federal do Brasil de 1988 faz previsão da dignidade da pessoa humana, em seu artigo $1^{\circ}$ (princípios fundamentais), inciso III, respaldando a dignidade humana em força normativa. Desta surgem outros direitos inerentes, tais como: direito à vida e à liberdade, o direito à intimidade e à honra, enfim, presta um norte aos direitos e garantias individuais.

Ora, o garantismo, ou o projeto garantista nas palavras de FELDENS (2008, p. 72), "passa por conferir aos direitos fundamentais um standard de garantias que os torne imunes contra a ação estatal arbitrária e, ao mesmo tempo, assegure-lhes, juridicamente, a necessária proteção frente a ameaças de terceiros". Por isso, MORAIS DA ROSA (2013, p. 34) considera a dignidade da pessoa humana e os direitos fundamentais como condições "que devem ser respeitados, efetivados e garantidos, sob pena de deslegitimação democrática da ação".

Iluminando o discurso, CesareBeccaria, da metade do século XVIII expos a necessidade da lei ser considerada uma garantia da dignidade humana e, também, um limitador dos arbítrios íntimos dos julgadores, principalmente frente aos resultados desumanos das penas:

À medida que as penas forem mais brandas, quando as prisões já não forem a horrível mansão do desespero e da fome, quando a piedade e a humanidade penetrarem nas masmorras, quando enfim os executores impiedosos dos rigores da justiça abrirem os corações à compaixão, as leis poderão contentar-se com indícios mais fracos para ordenar a prisão.

Por certo a luta e a reflexão de BECCARIA, ainda mais quando o maniqueísmo de interesses específicos (público - privado) - revestidos pela roupagem de um fazer o certo para o coletivo - tem o fim especial de legitimar e "pretender justificar o abuso de poder" (LOPES JR., p. 63). Ora,

Ademais, em matéria penal, todos os interesses em jogo - principalmente os do réu - superam a esfera do 'privado', situando-se na dimensão de direitos e garantias fundamentais (portanto, 'público', se preferirem). Na verdade, são verdadeiros direitos de todos e de cada um de nós, em relação ao (ab) uso de poder estatal.
Em outras palavras, falar de dignidade da pessoa humana e, assim, falar de direitos fundamentais, é buscar legitimar um processo penal democrático e de direitos, impondo limites ao poder de violência do Estado frente ao indivíduo, não somente pelas penas aplicadas que devem ser legitimas e proporcionais, mas pelo próprio caminhar processual que deve ser revestidos destas garantias. Ora, em qualquer momento que se assegure critérios disformes com a constituição e com a dignidade da pessoa humana, dificilmente estar-se-á dando tratamento constitucional ao réu e, nesta lógica, visível que o poder político refletido no processo é de um Estado autoritário.

\section{EXISTE LIMITE DE TEMPO PARA A PERSECUÇÃO PENAL?}

Por quanto tempo estaria o Estado legitimado a manter uma persecução penal? Ora, se um indiciado tem um inquérito contra si em um eterno aguardar para processar, cogente a violência institucionalizada valorada nesta inércia. Deve ser registrado que "É inegável que o IP gera, no mínimo, uma intranquilidade real e inequívoca para o sujeito passivo, que pode ser inclusive mais grave que a pena eventualmente aplicável ao caso" (AURY, p. 319). A Constituição Federal de 1988, em seu artigo 5o-, inciso LXXVIII - que pode ser compreendido como ramificação a assegurar a pessoa humana dignidade -, prevê que “a todos, no âmbito judicial e administrativo, são assegurados a razoável duração do processo e os meios que garantam a celeridade de sua tramitação”. Logo, trata-se de garantia constitucional a duração razoável da investigação criminal (administrativo) e do processo penal (judicial). Muito além, é uma garantia prevista na Convenção Europeia, no Pacto Internacional sobre Direitos Civis e Políticos e na Convenção Americana sobre Direitos Humanos (Pacto de San José de Costa Rica).

\begin{abstract}
Interessa ao acusado o julgamento rápido, fazendo cessar o constrangimento decorrente do processo, embora a demora possa ser-lhe favorável em virtude da possibilidade de ocorrer a prescrição da pretensão punitiva ou da pretensão executória. (FERNANDES, 2012, p. 126).
\end{abstract}

Contudo, o Superior Tribunal de Justiça tem norteado em suas decisões que o excesso de prazo não resulta de simples operação aritmética, devendo ser levando em conta a complexidade do processo, e, assim, o retardamento injustificado, os atos procrastinatórios da defesa e o número de réus envolvidos, são considerados como fatores que, se 
analisados em conjunto ou separadamente, indicam ser, ou não, razoável o prazo na formação da culpa. No entanto, a contrario senso, mesmo que a formação da culpa seja demorada, havendo a denúncia, este mesmo tribunal compreende que os vícios do inquérito, sem demonstração de prejuízos do réu, não impedem o prosseguimento do feito.

Não obstante o considerável lapso de tempo decorrido desde a instauração do inquérito policial, nenhum constrangimento ilegal por excesso de prazo para sua conclusão se evidencia na espécie, tendo em conta que o Paciente se encontra em liberdade e os autos do procedimento investigatório já foram encaminhados para o Ministério Público Federal. (HC 122.725/RJ, Rel. Ministra LAURITA VAZ, QUINTA TURMA, julgado em 04/10/2011, DJe 13/10/2011).

A alegação de excesso de prazo para a conclusão do inquérito policial e para o oferecimento da denúncia restou prejudicada, diante da informação de que o Juízo processante recebeu a inicial acusatória. (HC 228.014/PE, Rel. Ministra LAURITA VAZ, QUINTA TURMA, julgado em 16/02/2012, DJe 02/03/2012).

AGRAVO REGIMENTAL EM RECURSO ORDINÁRIO EM HABEAS CORPUS. EXCESSO DE PRAZO NA CONCLUSÃO DE INQUÉRITO POLICIAL. RECORRENTE EM LIBERDADE. INEXISTÊNCIA DE LESÃO À LIBERDADE DE LOCOMOÇÃO. RAZOABILIDADE DO PRAZO. DIVERSIDADE DE FATOS E PESSOAS INVESTIGADAS. RECURSO A QUE SE NEGA PROVIMENTO. 1. De acordo com a jurisprudência do Superior Tribunal de Justiça, o tempo despendido para a conclusão do inquérito assumiria relevância, caracterizando, de fato, constrangimento ilegal, se o recorrente estivesse preso durante o curso das investigações ou se o prazo prescricional tivesse sido alcançado nesse interregno e, ainda assim, a ação penal continuasse em andamento. No entanto, nenhuma dessas hipóteses se fez presente. 2. De mais a mais, a complexidade da causa justifica um maior cuidado na condução dos trabalhos de investigação e, por conseguinte, a dilatação dos prazos, nos termos do art. 10, $3^{\circ}$, do Código de Processo Penal. No caso, trata-se de investigação destinada a apurar "uma imensa pluralidade (passe a redundância) de fatos, aparentemente envolvendo quadrilha ou bando - para não falarmos em organização criminosa - integrado por mais de 20 (vinte) pessoas, em diferentes locais da Federação. 3. Agravo regimental a que de nega provimento. (AgRg no RHC 28.133/DF, Rel. Ministro MARCO AURÉLIO BELLIZZE, QUINTA TURMA, julgado em 21/06/2012, DJe 28/06/2012).
Em que pese à posição demonstrada, existem julgados da mesma Corte noutro sentido, para os quais o excesso do prazo na formação da culpa é sim motivo de trancamento do inquérito policial por não admitir que alguém seja constrangido a uma "investigação eterna":

[...] 5. No caso, passados mais de 7 anos desde a instauração do Inquérito pela Polícia Federal do Maranhão, não houve o oferecimento de denúncia contra os pacientes. É certo que existe jurisprudência, inclusive desta Corte, que afirma inexistir constrangimento ilegal pela simples instauração de Inquérito Policial, mormente quando o investigado está solto, diante da ausência de constrição em sua liberdade de locomoção (HC 44.649/SP, Rel. Min. LAURITA VAZ, DJU 08.10.07); entretanto, não se pode admitir que alguém seja objeto de investigação eterna, porque essa situação, por si só, enseja evidente constrangimento, abalo moral e, muitas vezes, econômico e financeiro, principalmente quando se trata de grandes empresas e empresários e os fatos já foram objeto de Inquérito Policial arquivado a pedido do Parquet Federal. 6. Ordem concedida, para determinar o trancamento do Inquérito Policial 2001.37.00.005023-0 (IPL $521 / 2001$ ), em que pese o parecer ministerial em sentido contrário. (HC 96666/MA, Rel. Ministro NAPOLEÃO NUNES MAIA FILHO, QUINTA TURMA, julgado em 04/09/2008, DJe 22/09/2008).

Deve ser observado que o direito ao prazo razoável não é somente para satisfazer o réu, como é também para que seja realizada a Justiça ${ }^{6}$. Contudo, este objetivo de fazer justiça, não pode fundamentar uma eterna perseguição, pois violaria igualmente um direito fundamental, por isso o dever de uma investigação em um prazo razoável. Conforme destacou BOBBIO (2004, p. 41), "não se pode instituir um direito em favor de uma categoria de pessoas sem suprimir um direito de outras categorias", e, exatamente por isso, no caso dos direitos, "não se pode proteger incondicionalmente um deles sem tornar o outro inoperante". Conclui-se, mesmo que ambicionado, nem tudo que se fabula ser merecedor de perseguição é realizável. Ora, um eterno procurar maculará um ou outro direito. Existe ao Estado, primeiro, um prazo razoável para ser eficiente no seu investigar e elucidar os fatos (inclusive punir), mas em determinado momento, quando esmoesse sua capacidade, deve parar esta perseguição.

\section{O QUE É (IN)DIVISIBILIDADE DA AÇÃO PÚBLICA?}

De maneira sucinta e na perspectiva de um processo penal democrático, MORAIS DA ROSA (2013, p. 92) 
enfrenta o tema do princípio da obrigatoriedade e da indivisibilidade da ação penal de iniciativa pública com tamanha envergadura jurídica:

[...] (princípio da Obrigatoriedade) não pode o jogador-autor negar-se a iniciar a partida por questões privadas. Decorrência do devido processo legal substancial é descabido o tratamento não isonômico, inexistindo disponibilidade sobre o conteúdo da ação penal. [...] (princípio da indivisibilidade) não pode [...] o Ministério Público escolher dentre os possíveis autores da infração somente alguns para figurar no processo. Pode manifestar-se pelo arquivamento em relação a alguns dos investigados e denunciar os demais. $\mathrm{O}$ que é vedado é imotivadamente deixar de promover a ação penal por critérios outros que não decorrentes da investigação preliminar.

Isso é dizer, sendo obrigatória e indisponível a ação pública, é um contra senso sustentar sua divisibilidade. Logo, bem capturado por LOPES JR. (2013, p. 318), “o que está a legitimar é a possibilidade de não denunciar alguém ou algum delito neste momento, para fazêlo posteriormente, atendendo ao interesse e a estratégia do acusador". Ou, nas palavras de RANGEL (2012, p. 233), havendo as condições mínimas para promover a ação penal "deve (princípio da obrigatoriedade) a ação ser proposta em face de todos (indivisibilidade)".

O Supremo Tribunal Federal diz que só a ação penal de iniciativa privada é que é indivisível, por força expressa do art. 48 do CPP, mas não a de iniciativa pública. Afirmativa errônea, pois a indivisibilidade da ação penal pública está expressa no art. 77, I, c/c 79, ambos do CPP. Assim, a ação penal pública também é indivisível como consequência lógica do princípio da obrigatoriedade da ação penal púbica. (RANGEL, 2012, p. 233).

Enfim, por indivisibilidade da ação penal, compreende PACELLI (2013, p. 151) ser a impossibilidade de fracionar a persecução penal contra um ou outro agente, deixando-se os demais excluídos da imputação delituosa. Enfrenta o autor a matéria em relação a ação penal pública:

Em tema de indivisibilidade, cumpre, por último, ressaltar que a regra não se aplica evidentemente às ações penais públicas, pautadas, como já visto, pelo princípio da obrigatoriedade. Assim, sendo o órgão da acusação obrigado a propor ação penal, é ele obrigado a fazê-lo em relação a todos os autores do fato, sendo desnecessário o recurso à regra da indivisibilidade (PACELLI, 2013, p. 155).
Importante destacar que esta não é posição absoluta da doutrina, assim como dos Tribunais. Por exemplo, GRECO FILHO (2012, p. 136) anota que nos casos de ação pública o processo pode ser sempre desmembrado, em razão da conveniência da instrução criminal. Porém, o autor ressalva: "É certo que o princípio da necessidade impõe sempre ação penal contra todos os autores da infração [...] Havendo omissão, enquanto não extinta a punibilidade, pode ser suprida pela adequada denúncia". Desta feita, pode-se notar que existe um norte no sentido de que a obrigatoriedade tornaria, sim, indivisível a ação penal pública, em que pese à doutrina contrária.

\section{PODEMOS FALAR EM ARQUIVAMENTO IMPLÍCITO}

Contextualizado o debate por meio de categorias próprias do processo penal e da dignidade da pessoa humana, resta evidente que o processo penal não pode ser visto como uma pena, mesmo que seja sentido pelo acusado como um lugar que o sofrimento se faz inevitável. Importa observar que falar de dignidade da pessoa humana é dar um norte constitucional reconhecendo a fragilidade do réu enquanto indivíduo frente a um Estado de extenso poder. Ora, o que deve ser limitado são os poderes, ainda mais quando revestidos de autoritarismo exacerbado.

Poder-se-ia dizer, pensando as categorias do processo penal da parte débil ou hipossuficiente ${ }^{7}$, que o reconhecimento do arquivamento implícito é uma garantia constitucional prevista em seus princípios norteadores. Pois, antes de se falar de uma eterna perseguição pelo Estado ao indivíduo e de obscurecimento da ação penal para uma conveniência estratégica. Em uma hipótese inicial, é mais eloquente impor ao Estado acusador que ao se omitir na denuncia em relação a um dos réus, somente volte a persegui-lo penalmente com novos elementos de prova, do que libertar sua violência em face de um indivíduo que não conhecerá as regas do jogo. Ora, toda a ação (ou não ação) do Estado, gera expectativas em seus interlocutores, sendo que para respaldar a dignidade da pessoa humana, defende-se que o mais republicano é uma imposição de obrigação de fazer ao Estado, seja denunciando a todos os autores ou manifestando por diligências contra alguns; seja arquivando contra determinados sujeitos; o que não se pode defender é a omissão sem qualquer previsão de garantia ao indiciado. Logo, se no momento anterior a denuncia omissa havia ou não havia elementos para acusar o réu, a forma de agir do acusador (não fazer), impõe reconhecer uma precariedade as formas e, assim, o arquivamento tácito. 
Uma vez sendo reconhecido o arquivamento, somente será reparada a omissão e autorizado o aditamento da denúnciaquando houver novos elementos.

Apesar do termo serarquivamento implícito, o que está sendo rechaçado, em verdade, é a continuidade irregular, obscura e desregrada do inquérito policial. Observa-se que o Inquérito Policial,enquanto elemento de informação, temem sua natureza precária um valor menor que o bem jurídico liberdade (física e psicológica) de um indivíduo.

$O$ indiciado que não é denunciado cria uma expectativa positiva, qual seja, regressão do seu estado de indiciado (probabilidade) para um estado no qual deixa de ser considerado inclusive suspeito (possibilidade). Logo, esta nova condição decorrente da omissão de seu nome na denúncia gera sim um direito de considerar haver arquivado o inquérito policial que antes corria em desfavor de sua pessoa. Do contrário, a inércia criada pela não ação do Ministério Público geraria uma violência silenciosa, um esperar indefinido, muito além dos conhecidos e notórios (perdas de) prazos para mover a ação penal. Isto, pois, já haverá uma ação penal sobre o fato delituoso, sendo que o seu nome e seu direito de ampla defesa não estará acionado, podendo (ou não) ser chamado a compor ao processo instante antes de uma sentença final, quando tratar-se de aditamento da denúncia, ou sabe-se lá quanto tempo se for trabalhar a possibilidade de uma nova ação autônoma.

Eis a garantia do arquivamento implícito, assegurar a este antes indiciado, que retorne a um status antes de suspeitoe, assim, somente poderá haver novas diligências e ação penal "com novos elementos de prova", o que obrigaria sua chamada e nova progressão ao estado de indiciado. Desta forma, e somente assim, será assistido e assegurando ao indivíduo suas garantias constitucionais.

\section{REFERÊNCIAS}

CARVALHO, Salo. Criminologia, Garantismo e teoria crítica dos direitos humanos: aportes iniciais. Revista do Instituto de Hermenêutica Jurídica, v. 07, p. 127-148, 2009.

CARNELUTTI, Francesco. As misérias do processo penal. São Paulo: Editora Pillares, 2009.

COSTA, José de Faria. Noções fundamentais de direito penal: fragmenta iuris poenalis. 2. ed. Portugal: Coimbra, 2010.

DEBORD, Guy. A sociedade do espetáculo: comentários sobre a sociedade do espetáculo. Rio de Janeiro: Contraponto, 1997.

BOBBIO, Norberto. A era dos direitos. Rio de Janeiro: Elsevier, 2004.

FELDENS, Luciano. Direito fundamentais e direito penal: garantismo, deveres de proteção, princípio da proporcionalidade, jurisprudência constitucional penal, jurisprudência dos tribunais de direitos humanos. Porto Alegre: Livraria do Advogado, 2008.

FERNANDES, Antonio Scarance. Processo penal constitucional. 7. ed. rev., atual. e ampl. São Paulo: Editora Revista dos Tribunais, 2012.

FRAGOSO, Heleno Cláudio. Lições de direito penal: parte geral: arts. $1^{\mathrm{O}}$ a 120. 5. ed. Rio de Janeiro: Forense, 1983.

GRECO FILHO, Vicente. Manual de processo penal. 9. ed. rev. e atual. São Paulo: Saraiva, 2012.

JARDIM, Afrânio Silva. Direito processual penal. 11. ed. Rio de Janeiro: Forense, 2003.

LOPES JR., Aury. Direito processual penal. 10 ed. São Paulo: Saraiva, 2013.

LIMA, Renato BRASILEIRO de. Curso de processo penal. Niterói: Impetus, 2013.

MORAIS DA ROSA, Alexandre. Guia compacto do processo penal conforme a teoria dos jogos. 1. ed. Rio de Janeiro: Lumen Juris, 2013.

PACELLI, Eugênio. Curso de processo penal. 16. ed. São Paulo: Atlas, 2012.

PRADO, Geraldo. Em torno da jurisdição. Rio de Janeiro: Lumen Juris, 2010.

RANGEL, Paulo. Direito processual penal. 20. ed. São Paulo: Atlas: 2012.

SHECAIRA, Sérgio Salomão. Criminologia. 4. ed. rev. e atual. São Paulo: Editora Revista dos Tribunais, 2012.

TÁVORA, Nestor; ALENCAR, Rosmar Rodrigues. Curso de direito processual penal. 8. ed. Salvador: Juspodivm, 2013.

ZAFFARONI, Eugenio Raúl. Manual de direito penal brasileiro: parte geral. 9. ed. São Paulo: Revista dos Tribunais, 2011. v. 1.

\section{NOTAS}

1 Especialista em Direito Empresarial pela FSG (Caxias do Sul, RS);Advogado; Coordenador do curso de pós-graduação em Direito Penal e Processo Penal na Estácio-FIB (Salvador, BA).

2 Por exemplo, na perspectiva da teoria de Labelling Approach, quando esta questiona "por que é que algumas pessoas são tratadas como criminosos, quais as consequências desse tratamento e qual a fonte de sua legitimidade?" (SHECAIRA, 2012, p. 254).

3 Nas palavras de Jorge de Figueiredo Dias: "Sob esta designação quer-se compreender todo o Estado democrático e social que mantém intocada a sua ligação ao direito, e mesmo a um esquema rígido de legalidade, e se preocupa por isso antes de tudo com a consistência dos direitos, das liberdades e das garantias da pessoa; [...] Não se trata pois tanto aqui de tomar qualquer posição na moderna controvérsia acerca da subsistência do estado-providência ou do regresso a um Estado-liberal, quanto de caracterizar o Estado, fundamentalmente e na sua acepção social mais lata, como um Estado de JustiçaI" (2007, p. 26 e 27).

4 Nesse sentido Antonio Scarance Fernandes leciona, mas também adverte ser o "processo penal, especialmente por trabalhar com um bem fundamental do ser humano, a sua liberdade, reflete a concepção política dominante e o seu modo de tratar os direitos, as garantias do suspeito, do acusado e os interesses dos órgãos incumbidos da persecução penal".

5 Neste sentido defendem Nestor Távora e Aury Lopes Jr.

6 Luciano Feldens (2008, p.103 e s.s.) traz para o debate o caso Damião Ximenes Lopes versus Brasil, da Corte Interamericana (CIDH) a qual, ao condenar o Estado brasileiro, destacou o autor: "O Estado deve garantir que em um prazo razoável o processo interno destinado a investigar e sancionar os responsáveis pelos fatos deste caso surta seus devidos efeitos, conferindo aplicabilidade direta no direito interno às normas de proteção da Convenção Americana".

Situação muito bem identificada por Aury Lopes Jr. 